\title{
Morphological trait matching shapes plant-frugivore networks across the Andes
}

Irene M.A. Bender ${ }^{1,2,3}$, W. Daniel Kissling ${ }^{4}$, Pedro G. Blendinger ${ }^{5}$, Katrin Böhning-Gaese ${ }^{1,3,6}$, Isabell Hensen ${ }^{1,2}$, Ingolf Kühn ${ }^{7,2,1}$, Marcia C. Muñoz ${ }^{3,6}$, Eike Lena Neuschulz ${ }^{3}$, Larissa Nowak ${ }^{3,6}$, Marta Quitián ${ }^{3,6}$, Francisco Saavedra $^{8}$, Vinicio Santillán ${ }^{3,6}$, Till Töpfer ${ }^{9}$, Thorsten Wiegand ${ }^{1,10}$, D. Matthias Dehling ${ }^{3,11}$, Matthias Schleuning ${ }^{3}$

${ }^{1}$ German Centre for Integrative Biodiversity Research (iDiv) Halle-Jena-Leipzig, 04103 Leipzig, Germany

${ }^{2}$ Institute of Biology, Geobotany and Botanical Garden, Martin Luther University Halle-Wittenberg, 06108

Halle, Germany

${ }^{3}$ Senckenberg Biodiversity and Climate Research Centre, 60325 Frankfurt (Main), Germany

${ }^{4}$ Institute for Biodiversity and Ecosystem Dynamics (IBED), University of Amsterdam, POSTBUS 94248,1090

GE Amsterdam, the Netherlands

${ }^{5}$ Instituto de Ecología Regional, Consejo Nacional de Investigaciones Científicas y Técnicas (CONICET) -

Universidad Nacional de Tucumán, CC 34, 4107 Tucumán, Argentina

${ }^{6}$ Goethe University Frankfurt, Institute for Ecology, Evolution \& Diversity, Biologicum, 60439 Frankfurt (Main),

Germany

${ }^{7}$ Helmholtz Centre for Environmental Research - UFZ, Dept. Community Ecology, 06120 Halle, Germany

${ }^{8}$ Herbario Nacional de Bolivia (LPB), Instituto de Ecología, Universidad Mayor de San Andrés, Campus

Universitario Cota Cota, c. 27, casilla 10077, La Paz, Bolivia

${ }^{9}$ Zoological Research Museum Alexander Koenig, 53113 Bonn, Germany

${ }^{10}$ Helmholtz Centre for Environmental Research - UFZ, Dept. Ecological Modelling, 04318 Leipzig, Germany

${ }^{11}$ Centre for Integrative Ecology, School of Biological Sciences, University of Canterbury, Private Bag 4800,

Christchurch 8140, New Zealand

Corresponding author: Irene M.A. Bender, German Centre for Integrative Biodiversity Research (iDiv) HalleJena-Leipzig, 04103 Leipzig, Germany. Email: bender.ima@gmail.com

Decision date: $19-$ Feb-2018

This article has been accepted for publication and undergone full peer review but has not been through the copyediting, typesetting, pagination and proofreading process, which may lead to differences between this version and the Version of Record. Please cite this article as doi: [10.1111/ecog.03396].

'This article is protected by copyright. All rights reserved'. 


\begin{abstract}
Interactions between resource and consumer species are organized in ecological networks. Species interactions in these networks are influenced by the functional traits of the interacting partners, but the generality of trait-based interaction rules and the relationship between functional traits and a species' specialization on specific interaction partners are not yet understood. Here we combine data on eight interaction networks between fleshy-fruited plants and frugivorous birds sampled across the tropical and subtropical Andean range. We test which combinations of morphological plant and animal traits determine trait matching between resource and consumer species in these networks. In addition, we test which of the morphological traits influence functional specialization of plant and bird species. In a meta-analysis across network-specific fourth-corner analyses, we found that plant-animal trait pairs related to size matching (fruit size-beak size) and avian foraging behavior (plant height-wing shape and crop mass-body mass) were positively related in these networks. The degree of functional specialization on specific interaction partners was positively related to crop mass in plants and to the pointedness of the wing in birds. Our findings show that morphological trait matching between fleshy-fruited plants and frugivorous birds is a general phenomenon in plant-frugivore networks across the Andes and that specific plant and bird traits can be used to approximate the degree of functional specialization. These insights into the generality of interaction rules are the base for predictions of species interactions in ecological networks, for instance in novel communities in the future, and can be applied to identify plant and animal species that fulfill specialized functional roles in ecological communities.
\end{abstract}

'This article is protected by copyright. All rights reserved'. 


\section{Introduction}

Species interactions in ecological communities are often influenced by the degree of trait matching between potential partners (Wheelwright 1985, Woodward and Warren 2007, Stang et al. 2009, Dehling et al. 2014, Maglianesi et al. 2015). For instance, size matching describes the phenomenon that large predators tend to interact with large prey species, whereas small predators are usually constrained to small-sized prey species (Cohen et al. 1993, Woodward and Warren 2007, notable exceptions include large marine mammals, Tucker et al. 2016). It should therefore be possible to infer interaction rules from the traits influencing the matching of potential partners (Gravel et al. 2013) since the likelihood of interactions increases with the degree of trait matching in many interaction systems (Levey 1987). Knowledge about trait matching rules that govern the interactions between resource and consumer species can be used to make projections about which pairs of species are likely to interact in current or potential future communities (Morales-Castilla et al. 2015, Bartomeus et al. 2016). The first step towards such projections is to identify general interaction rules based on matching traits across interaction networks sampled at different localities (Kissling and Schleuning 2015).

Matching traits also define a species' functional role in interaction networks (Schleuning et al. 2015). This follows from the concept of the Eltonian niche (Elton 1927, Chase and Leibold 2003), which assumes that species that interact with different sets of interaction partners fulfill different functional roles in ecological communities. In interaction networks, the functional role of species is therefore most accurately described by the functional traits of their interaction partners (Dehling et al. 2016, Bender et al. 2017). Since species differ widely in their functional roles, e.g., in their degree of specialization on specific partners (Waser and Ollerton 2006,

Olesen et al. 2011a, Bender et al. 2017), species that interact with a set of species with which few other species interact are functionally specialized in respect to the co-occurring species (Dehling et al. 2016). These functional specialists can provide ecological functions that no or few other species can provide and may be considered especially important for the interaction network and the entire ecosystem (Mello et al. 2015, Sebastián-González 2017). Since data on species interactions are notoriously difficult to record (Jordano 2016), it would be desirable to approximate the degree of functional specialization of plant and animal species directly from their own morphological traits. One possibility to get a more general understanding of the types of species that contribute specialized functional roles to ecological networks is therefore to identify matching traits that are associated with a high degree of functional specialization across networks from different localities.

'This article is protected by copyright. All rights reserved'. 
Matching traits have been previously identified in studies of mutualistic plant-animal interaction networks (Wheelwright 1985, Jordano 1987, Stang et al. 2009, Dehling et al. 2014, Maglianesi et al. 2015) and can be categorized into two groups. The first group consists of traits which relate to the matching between plant and animal size (size matching) and correspond, for instance, to a matching between flower or fruit size and the respective animal organs, such as proboscis or bill size (Wheelwright 1985, Stang et al. 2009, Garibaldi et al. 2015, Sebastián-González et al. 2017). Second, matching traits can be related to the foraging behavior of consumers and are, for instance, related to traits associated with animal mobility, such as avian wing shape, and the location of plant resources, such as forest stratum (Moermond and Denslow 1985, Schleuning et al. 2011). Additionally, consistent with the theory of optimal foraging, large species require energy-rich resources (Belovsky 1997, Petchey et al. 2008). Therefore, animals with a large body size tend to prefer energy-rich resources (Krebs and Davies 1993). Since different traits, and the combination of these traits, influence the matching of species in interaction networks, the same traits may also influence the degree of functional specialization within networks (Dehling et al. 2016) and may be used to identify species with important functional roles in networks (Sebastián-González 2017). Most previous work on trait matching and functional specialization in mutualistic networks has focused on specific localities and on the consumer perspective (e.g., Coux et al. 2016, Dehling et al. 2016, Bender et al. 2017).

Here, we conduct a large-scale analysis across mutualistic seed-dispersal networks to compare the importance of different pairs of matching traits for both the degree of trait matching and the functional specialization of plant and animal species in these networks. To this end, we combined eight interaction networks from five different countries stretching the tropical and subtropical Andean range to identify general interaction rules in plantfrugivore networks. The Andean mountain range is a global diversity hotspot for both fleshy-fruited plants (Jansson and Davies 2008) and frugivorous birds (Kissling et al. 2009). This diversity, in combination with the wide geographical range of the Andes, makes it an ideal region to test the generality of trait matching and to identify functional traits that determine functional specialization in plant-frugivore networks.

Specifically, we ask (i) which trait pairs influence the matching between plants and animals, and (ii) which traits influence the functional specialization of plants and animals across networks. We expect that (i) trait pairs related to size matching will be more important in shaping plant-animal interactions than foraging-related trait pairs, because size matching imposes direct constraints on the likelihood of interactions (Wheelwright 1985,

'This article is protected by copyright. All rights reserved'. 
Sebastián-González et al. 2017). In addition, we expect that (ii) large-fruited plants and large-billed bird species show the highest level of functional specialization across networks because these species are reciprocally specialized on each other (Moermond and Denslow 1985, Wheelwright 1985) and are relatively rare in the respective communities (Wheelwright 1988).

\section{Methods}

\section{Interaction networks}

We combined data from interaction networks between fleshy-fruited plants and frugivorous birds collected at eight different locations across the Andes. The eight networks included two networks from Colombia, two networks from Ecuador, two networks from Peru, one network from Bolivia and one network from Argentina (Fig. 1). The networks cover an elevation range from 1000 to $3000 \mathrm{~m}$ a.s.l. (hereafter "m") and extend from $4.7^{\circ} \mathrm{N}$ to $26.5^{\circ} \mathrm{S}$, covering a large portion of the tropical and subtropical Andean range. All networks were collected in near-natural forest, i.e., networks from highly fragmented or intensively disturbed forests were not considered in the analyses because the importance of species traits may be weakened in disturbed, impoverished communities (Saavedra et al. 2014).

All networks comprise information on the frequency of visits of frugivorous bird species on fleshy-fruited plant species (weighted networks). We only included true seed-dispersal events in the analyses that correspond to fruit swallowing or carrying-away. Sampling effort was high in all networks (range of sampling hours: 300 - 960, mean $=606$, standard deviation $=224$ ), but the number of observed interaction events varied among networks (range of observed interaction events: $241-4988$, mean $=1447, \mathrm{SD}=1539$ ). The network sampled in Bolivia was the smallest network comprising 19 plant and 22 bird species. The largest network from Peru comprised 52 plant and 61 bird species (Fig. 1). Overall, we analysed 227 plant species interacting with 180 bird species in 11,578 interaction events. The most species rich plant genus was Miconia (Melastomataceae) with 39 species. The largest group of birds were the tanagers (genus Tangara, 19 species, family Thraupidae). A more detailed description of the sampling of each network is given in Appendix 1.

To assess the sampling completeness of each network (Chacoff et al. 2012), we generated accumulation curves of the observed bird richness and the number of interaction pairs (link richness) and calculated the asymptotic bird and link richness based on the Chao richness estimator (Oksanen et al. 2015). All interaction

'This article is protected by copyright. All rights reserved'. 
networks were similarly well sampled, as indicated by the saturating trends in the accumulation curves (Figs. A1, A2). Bird richness approached the asymptotic richness in all networks (Fig. A1).

\section{Morphological traits}

Morphological traits were collected for all plant and bird species observed in the interaction networks. We selected traits that were identified as key matching traits in plant-frugivore networks in the Peruvian Andes (Dehling et al. 2014). Plant traits included fruit diameter ( $\mathrm{mm})$, fruit length ( $\mathrm{mm})$, plant height (m) and crop mass (g, number of fruits per plant multiplied by mean individual fruit mass). Fruit length, fruit diameter and fruit mass were measured on at least 20 fruits per species collected from one to three individuals, depending on availability. Plant height and number of fruits were measured on all individuals of a species present in a plot. Bird traits included bill width ( $\mathrm{mm})$, bill length ( $\mathrm{mm})$, wing shape (i.e., Kipp's index as a measure of the pointedness of the wing) and body mass (g). Kipp's index was calculated by dividing the Kipp's distance (the distance between the tip of the first secondary and the wing tip, measured on the folded wing, Leisler and Winkler 1991) by wing length. A high Kipp's index indicates a wing shape which enables birds to fly over long distances, whereas a low Kipp's index indicates rounded wings that are especially suited for high maneuverability in dense vegetation (Rayner 1988). Bird traits were measured on at least four museum specimens, body mass was collected from the literature (Dunning 2007). Trait data for all eight interaction networks were collected using the same methodologies.

We log-transformed plant traits (fruit diameter, fruit length and crop mass) and bird traits (bill width, bill length and body mass) prior to the analysis to approximate a normal distribution of trait data. Plant height and Kipp's index were not log-transformed since these traits did not deviate from a normal distribution.

\section{Trait matching}

In order to identify which trait combinations shape plant-animal matching across sites, we used a modified version of the fourth-corner analysis. The fourth-corner analysis was initially proposed to measure and test the relationship between species traits and environmental variables (Legendre et al. 1997, Dray and Legendre 2008). Dehling et al. (2014) modified this approach to test the relationship between plant traits and bird traits. They used the species interaction matrix $\mathbf{L}$ between plants and birds (plant species*bird species, unit: interaction strength,

'This article is protected by copyright. All rights reserved'. 
the proportion of visits of a frugivore species to each plant species; Bascompte and Jordano 2007) to compare a matrix $\mathbf{R}$ of plant traits (plant species*plant traits) with a matrix $\mathbf{Q}$ of bird traits (bird species*bird traits). The objective of the fourth corner analysis is then to estimate the parameters of a fourth matrix $\mathbf{X}$ (plant traits* bird traits) that quantifies the correlation between pairs of plant and bird traits.

For each network, we tested four pairs of plant and bird traits (Dehling et al. 2014): fruit diameter vs. bill width, fruit length vs. bill length, plant height vs. Kipp's index, crop mass vs. body mass. We used a null model (i.e., testing for the null hypothesis $\mathbf{X}=0$ ) to test whether the traits of plants and birds were significantly correlated (i.e., $\mathbf{X} \neq 0$ ). Null model testing is complex because it involves the relationships of the interaction matrix $\mathbf{L}$ to both plant traits $\mathbf{R}$ and bird traits $\mathbf{Q}$. A proposed solution is to first remove the relationship between plant traits and observed interactions by permutating plant identities in the interaction matrix $\mathbf{L}$ and then to remove the relationship between bird traits and the observed interactions by permutating the bird identities in the interaction matrix L (Dray and Legendre 2008, Ter Braak et al. 2012). This approach has been implemented as permutation model type 6 (fourthcorner in 'ade4' package in R, Dray and Legendre 2008), which combines the output of model type 2 (plant species of the interaction matrix are permuted) and model type 4 (bird species of the interaction matrix are permuted) and selects the larger of the two $P$ values of the two permutation types (Ter Braak et al. 2012).

We extracted the Pearson's correlation coefficients $r$ for each trait pair from the matrix $\mathbf{X}$ of the individual fourth-corner analyses for each of the eight networks. To generalize the individual fourth-corner results for the entire Andean range, we performed a meta-analysis (metacor.DSL in 'metacor' package in R, Laliberté 2011) across the Pearson's correlation coefficients $r$ of the eight individual fourth-corner analyses. Prior to the metaanalysis, we applied Fisher's z-transformation to the correlation coefficients to approximate a normal distribution of $r$ (escalc in 'metafor' package in R, Viechtbauer 2010). We performed this meta-analysis in two ways. First, we defined the square-root of the total number of interactions observed in each network as sample size for each network and weighted the meta-analysis by this measure of sampling effort since the accuracy of fourth-corner correlations in network analyses increases with the total number of observed interactions (see Appendix S2 in Dehling et al. 2014). Second, we quantified the sampling completeness of each network by dividing the number of observed links by the asymptotic link richness, based on the Chao estimator, and weighted the meta-analysis by sampling completeness.

'This article is protected by copyright. All rights reserved'. 


\section{Functional specialization}

As a measure for functional specialization, we calculated the functional originality, the extent to which species interact with partners that only few other species interact with (Dehling et al. 2016) for all plant and bird species. First, plant traits of all networks were combined in a single trait matrix. Pairwise Mahalanobis distances between all plant species were calculated and used in a Principal Coordinates Analysis (PCoA). This analysis resulted in four axes that represent the total variation in plant traits across all networks. Second, to determine the functional originality of bird species in each network, we selected all plant species that a specific bird species interacted with in the respective network. We averaged the PCoA coordinates of these plant species weighting them by the respective interaction strength (Bascompte and Jordano 2007). This resulted in a weighted interaction centroid of a bird species in plant trait space (Dehling et al. 2016). Third, we calculated the community centroid as the unweighted mean of the interaction centroids of all bird species present in the respective network. Functional originality was then measured as the Euclidian distance between the interaction centroid of a specific bird species and the community centroid (Dehling et al. 2016). A high functional originality value indicates that a bird interacted mostly with plant species characterized by traits that only few other bird species interacted with. We repeated the analogous procedure for the plant species and here defined the functional originality of plant species in a four-dimensional bird trait space based on the PCoA coordinates derived from bill width, bill length, wing shape and body mass. Functional originality values of plant and bird species were log-transformed to approximate a normal distribution of values. These values were scaled to a mean of 0 and a standard deviation of 1 across networks, which ensures that model estimates were comparable between plant and bird species.

We aimed at identifying which plant and bird traits were most closely associated with species' functional specialization. To identify the relative importance of the four functional plant (fruit diameter, fruit length, plant height and crop mass) and bird traits (bill width, bill length, wing shape and body mass), we fitted linear mixedeffect models ('Ime4' package in R, Bates et al. 2015) across all species in the eight networks, separately for plants and birds. In the two overall models, we thus fitted species' functional originality as the response variable and the four functional plant or bird traits as predictor variables. Prior to model fitting, functional traits of plants and birds were standardized to a mean of 0 and a standard deviation of 1 across networks which ensures that model estimates are comparable among traits. All models included 'network identity'as a random effect to

'This article is protected by copyright. All rights reserved'. 
account for the fact that estimates of functional originality were derived from different networks. In addition, 'species identity' was included as a random effect because a species could occur in more than one network. We initially included also higher-level taxonomic information (i.e., genus and family). However, because this resulted in qualitatively identical results we omitted these terms from the final models in the interest of parsimony. In order to correct for differences in sampling effort among networks, we weighted estimates of functional originality for each species by sampling effort, i.e., the square-root of the total number of interactions observed in the respective network.

To identify the best model, we first fitted all possible submodels (dredge in 'MuMIn' package in R, Barton 2016) of the global models. To avoid collinearity among predictors, we constrained the resulting set of models to exclude models where traits with a correlation coefficient higher than $|0.5|$ were combined. For plant species, fruit diameter and fruit length $(r=0.74)$ and crop mass and fruit diameter $(r=0.54)$ were highly correlated, while for bird species this was the case for bill width and bill length $(r=0.90)$, bill width and body mass $(r=0.85)$ and bill length and body mass $(r=0.84)$. We compared the resulting set of sub-models according to the Akaike information criterion corrected for small sample size (AICc, Burnham and Anderson 2002). We obtained the variable importance (i.e., the summed Akaike weights of all models including the respective predictor variable) and weighted mean model coefficients across all models with a $\triangle \mathrm{AICc}$ value smaller than 2 relative to the best model with the lowest AICc value (full model estimates derived from model.avg in 'MuMIn' package in R, Barton 2016).

\section{Results}

\section{Trait matching}

The meta-analysis across the eight Andean interaction networks, weighted by sampling effort, showed a strong signal of trait matching for all pairs of plant and frugivore traits (Fig. 2). Contrary to our expectation, there was no major difference in the correlation strength between traits related to size matching and foraging strategy. Fruit diameter vs. bill width $(r=0.32, P<0.001)$ and plant height vs. wing shape $(r=0.33, P<0.001)$ showed the highest correlations across networks. The correlations between fruit length vs. bill length $(r=0.26, P<0.001)$ and crop mass vs. body mass $(r=0.21, P=0.02)$ were slightly weaker. The meta-analysis weighted by sampling completeness showed qualitatively identical results (Table A1). In the individual networks, correlation

'This article is protected by copyright. All rights reserved'. 
coefficients between the pairs of matching traits were more variable than in the meta-analyses (Fig. A3). Except for the crop mass-body mass relationship, trait correlations were always positive, consistent with the overall signal of trait matching across networks.

\section{Functional specialization}

In the eight analyzed networks, the highest degrees of functional specialization were found in the plant species Alchornea grandiflora (Euphorbiaceae, Colombia 1), Oreopanax caricifolium (Araliaceae, Colombia 2), Schefflera sp. (Araliaceae, Ecuador 1), Isertia laevis (Rubiaceae, Ecuador 2), Endlicheria sp. (Lauraceae, Peru 1), Clusia elliptica (Clusiaceae, Peru 2), Symplocos arechea (Symplocaceae, Bolivia) and Duranta serratifolia (Verbenaceae, Argentina). The most functionally specialized bird species in the networks were the Goldenheaded Quetzal (Pharomachrus auriceps, Trogonidae, Colombia 1), Masked Trogon (Trogon personatus, Trogonidae, Colombia 2), Ruddy Pigeon (Patagioenas subvinacea, Columbidae, Ecuador 1), Emerald Toucanet (Aulacorhynchus prasinus, Ramphastidae, Ecuador 2), Chestnut-tipped Toucanet (Aulacorhynchus derbianus, Ramphastidae, Peru 1), Blue-banded Toucanet (Aulacorhynchus coeruleicinctis, Ramphastidae, Peru 2), Blueand-black Tanager (Tangara vassorii, Thraupidae, Bolivia 2), and Crested Becard (Pachyramphus validus, Tityridae, Argentina). The majority of the functionally most specialized bird species did not belong to the Passeriformes although these are usually the most common birds in seed dispersal networks.

We identified specific plant and bird traits that explained the differences in functional specialization, i.e., the functional originality of species, among plant and bird species (Fig. 3). For plants, we identified two models with a $\triangle \mathrm{AICc}$ value smaller than 2 ; the best model included only crop mass $(\triangle \mathrm{AICc}=0)$ and the second-best model included crop mass and plant height $(\triangle \mathrm{AICc}=0.69)$. In the averaged model, crop mass was positively related to the degree of functional originality of plants $(\mathrm{b}=0.23, P<0.01)$, whereas the effects of plant height $(\mathrm{b}=0.04, P$ $=0.57$ ) was not significant (Fig. 3a). For birds, two models had a $\triangle$ AICc value smaller than 2 ; the best model included wing shape and bill length $(\triangle \mathrm{AICc}=0)$ and the second-best model included wing shape and body mass $(\triangle \mathrm{AICc}=1.84)$. In the averaged model, the pointedness of the wing $(\mathrm{b}=0.15, P=0.03)$ was positively related to the degree of functional originality of birds, whereas the effects of bill length $(b=0.10, P=0.24)$ and body mass ( $b=0.03, P=0.62$ ) were not significant (Fig. 3b).

'This article is protected by copyright. All rights reserved'. 


\section{Discussion}

We combined eight plant-frugivore interaction networks, sampled along the Andean range, to identify functional traits that determine the degree of trait matching and functional specialization of plants and animals. We found that plant and animal traits related to size matching (fruit size-beak size) and animal foraging (plant height-wing shape and crop mass-body mass) were important in shaping plant-frugivore interaction networks across the Andes. Specific plant and animal traits were only weakly associated with species' functional specialization across networks. Nevertheless, we detected that plant crop mass was positively related to the degree of functional specialization of plants, while the pointedness of the wing was positively related to the degree of avian functional specialization.

\section{Trait matching across the Andes}

Our meta-analysis across eight Andean interaction networks showed that plant and animal traits, both related to size matching and to animal foraging, determined the matching of plant and animal species in plant-frugivore networks. The importance of traits related to size matching is well studied in ecological interaction networks (Wheelwright 1985, Stang et al. 2009, Garibaldi et al. 2015). For instance, bird-dispersed fruits strongly depend on bird species that have a sufficiently large gape width that enables them to swallow the fruit (Levey 1987), insect and bird pollinators with a short proboscis or bill are constrained to visit short flowers (Stang et al. 2009, Maglianesi et al. 2015), and small predators are usually unable to feed on large prey (Cohen et al. 1993, Woodward and Warren 2007). This has resulted in the hypothesis that size matching is a general principle in ecological interactions (Olesen et al. 2011b). The results from our meta-analysis support this hypothesis.

In contrast to our initial expectation, we found that traits related to foraging strategies of frugivorous birds, were equally important as trait pairs related to size matching in shaping interaction networks. The shape of a bird's wing is related to its movement capacity and maneuverability (Rayner 1988). Rounded wings allow a bird to move in dense forest understory, while birds with pointed wings are better equipped for long-distance flights and foraging in the canopy (Moermond and Denslow 1985). Wing shape therefore directly influences where a bird species encounters fruits while foraging (Schaefer et al. 2002). In our networks, bird species with rather pointed wings were, for example, the Golden-headed Quetzal (Pharomachrus auriceps, Trogonidae) and the Masked Trogon (Trogon personatus, Trogonidae). These birds were also among the most functionally

'This article is protected by copyright. All rights reserved'. 
specialized birds in the networks. Wing shape has likewise been shown to influence flight maneuverability and foraging behavior in bats (Norberg and Rayner 1987, Swartz et al. 2003). This suggests that the influence of wing shape on interaction networks is a general phenomenon across different types of plant-frugivore networks.

The relationship between crop mass and body mass is consistent with the theory of optimal foraging (Krebs and Davies 1993, Belovsky 1997, Petchey et al. 2008). According to this theory, large bodied birds need to feed on energy-rich resources to meet their energetic demands (Corlett and Primack 2011). Large-bodied frugivores therefore feed mostly on plants with a large crop mass, which offer a high amount of resources accumulated in one place, while small bodied frugivores tend to visit several individuals of plants with small crops (Dehling et al. 2014, Howe 2016, Muñoz et al. 2017).

Despite the overall significant relationships between all trait pairs, the degree of trait matching differed among networks, especially in the case of the crop mass-body mass relationship. This could be due to differences in sampling effort and completeness among the studied networks. Previously, it has been shown that the likelihood to detect trait matching increases with the number of observed interaction events (Dehling et al. 2014). Moreover, we compared communities that differed widely in their species pools. For instance, maximum body size varied from $706 \mathrm{~g}$ (Peru $1 \& 2$, Bolivia) to $1180 \mathrm{~g}$ (Ecuador 2). Depending on the degree of trait variation and the dominance of specific trait values in a community, the detectability of trait matching may differ among networks (Dehling et al. 2014). For instance, we would expect that the degree of trait matching is weakened in modified ecological communities that are dominated by small-bodied species (Saavedra et al. 2014). Moreover, consumer species can respond flexibly to fluctuations in resource availability (Bender et al. 2017), which will also result in fluctuations in the degree of trait matching between plant and animal species. This variability does not question the overall importance of trait matching, here exemplified across the Andean range, but cautions against generalizations from species-rich to species-poor ecosystems.

\section{The relationship between functional traits and functional specialization}

While we expected that large-fruited plants and large-billed bird species show the highest level of functional specialization across networks, we found that the relationship between functional specialization and plant and bird traits was overall weak across the range of studied networks. Nevertheless, we were able to identify a single plant trait (crop mass) and a single bird trait (wing shape) that were significantly associated with functional

'This article is protected by copyright. All rights reserved'. 
specialization. Our results indicate that plants that produced a large crop mass attracted a morphologically distinct set of bird species compared to other plant species in the community. Since phylogenetically unrelated plant species were the functionally most specialized in each network, this finding suggests that specific trait values, rather than species taxonomy, are associated with plant functional specialization. Plant species with large crops might especially attract large-bodied birds (Dehling et al. 2014) that rely on such resources to meet their high energy demands (Krebs and Davies 1993). For instance, Clusia elliptica (Clusiaceae) interacted with the Blue-banded Toucanet (Aulacorhynchus coeruleicinctis), one of the largest frugivorous birds in the Peruvian bird community at $3000 \mathrm{~m}$ (Peru 2, body mass $=208 \mathrm{~g}$ ). In contrast, plants with small fruit crops are mostly visited by bird species with less distinct traits, such as the many tanager species. Hence, our findings suggest that plants with large crops attract, and potentially require, functionally more distinct seed dispersers than plants with small crops.

Bird species with pointed wings were identified to visit the most distinct set of plant species in the community. Across networks, bird species with a high degree of functional specialization were scattered across different taxonomic groups, indicating that functional specialization is related to specific trait values largely independent of species' phylogeny. Bird species with pointed wings usually feed in the canopy of the forest and are able to fly long distances (Moermond and Denslow 1985, Dehling et al. 2014). Due to their flight ability, these species can provide long-distance dispersal to plant communities (Böhning-Gaese et al. 2006). This is the reason why such species are particularly important for connecting forest patches in fragmented landscapes (Müller et al. 2014). According to our analyses, these species also provide seed-dispersal functions to specific types of plant species as they were functionally most specialized. While previous studies have highlighted that the loss of large-bodied animal species from tropical forests has severe consequences for the plant community (Galetti et al. 2013, Vidal et al. 2013), our results indicate that the loss of bird species with pointed wings might similarly have severe functional consequences for tropical forests.

Since we found a high degree of trait matching between individual trait pairs, we expected that functional specialization of plants and birds was determined by corresponding matching traits (e.g., large-fruited plants and large-billed bird species). However, the identified plant and bird traits, crop mass and wing shape, did not belong to the same trait pair, nor was there a high correlation between plant height and crop mass $(\mathrm{n}=243$ species, $r=$ $0.34, P<0.05)$ or wing shape and body mass ( $\mathrm{n}=304$ species, $r=0.22, P<0.05)$. This indicates that there are

'This article is protected by copyright. All rights reserved'. 
important differences in the types of traits that are associated with functional specialization in plant and bird communities. In plant communities, those species that invest comparatively little energy into their fruits are mostly dispersed by similar types of often small-bodied bird species (McKey 1975, Kessler-Rios and Kattan 2012). In contrast, the few plant species that invest into a large crop mass and attract a functionally distinct group of frugivorous birds might benefit from long-distance dispersal or from dispersal to different locations relative to other plant species in the community (Howe and Smallwood 1982). In bird communities, canopy-foraging birds with pointed wings follow a different strategy of fruit tracking than species with more rounded wings as they are able to move over longer distances and are, thus, able to reach specific types of fruit (Moermond and Denslow 1985). These bird species are likely to provide particularly valuable seed-dispersal functions to plant communities.

\section{Conclusion}

We found across a large geographic range that traits related to size matching and animal foraging shaped interaction frequencies between plants and birds in frugivory networks. The generality of trait matching is the base for predicting unknown interactions from species' functional traits in novel ecological communities (Kissling and Schleuning 2015), for instance as a result of species' migrations and local extinctions in response to climate change. Furthermore, we show that the degree of functional specialization of plants and birds is weakly, but significantly associated with specific morphological traits. The identification of these traits is useful for the identification of plant and bird species that fulfill functionally specialized roles in current and future communities.

\section{Acknowledgements}

We thank two anonymous reviewers for their constructive feedback on our manuscript. We gratefully acknowledge the support of the German Centre for Integrative Biodiversity Research (iDiv) Halle-Jena-Leipzig funded by the German Research Foundation (FZT 118). W.D.K. acknowledges a University of Amsterdam (UvA) starting grant. K.B.-G., D.M.D., E.L.N. and M.S. received support from the research funding program 'LOEWE—Landes-Offensive zur Entwicklung Wissenschaftlich-ökonomischer Exzellenz' of Hesse's Ministry of Higher Education, Research, and the Arts. DMD was also supported by a Marsden Fund Fast-Start Grant

'This article is protected by copyright. All rights reserved'. 
(UOC-1101) administered by the Royal Society of New Zealand. Furthermore, we are grateful to the members of the Laboratorio de Ecología de Aves - IER for their help in the field in Argentina. The study in Argentina was funded by CONICET (PIP 2009-1025 and 2014-592) and ANPCyT (PICT 2013-1280). Permission for conducting research in Parque Sierra de San Javier was granted by the Universidad Nacional de Tucumán. The study in Colombia was funded by Rufford Small Grant for Nature Conservation (\# 11042-1), and the Graduate Student Scholarship "Francisco José de Caldas", COLCIENCIAS (Departamento Administrativo de Ciencia, Tecnología e Innovación Republica de Colombia). The study in Ecuador was funded by the German Research Foundation (DFG) in the framework of the Research Unit 823-825 "Platform for Biodiversity and Ecosystem Monitoring and Research in South Ecuador" (PAK 825/1; BO 1221/20-1).

'This article is protected by copyright. All rights reserved'. 


\section{Literature cited}

Bartomeus, I. et al. 2016. A common framework for identifying linkage rules across different types of interactions. - Funct. Ecol. 30:1894-1903.

Barton, K. 2016. MuMIn: Multi-Model Inference. R package version 1.15.6. http://CRAN.Rproject.org/package=MuMIn.

Bascompte, J. and Jordano, P. 2007. Plant-animal mutualistic networks: the architecture of biodiversity. - Annu. Rev. Ecol. Evol S. 38:567-93.

Bates, D. et al. 2015. Fitting linear mixed-effects models using lme4. - J. Stat. Softw. 67:1-48.

Belovsky, G.E. 1997. Optimal foraging and community structure: the allometry of herbivore food selection and competition. - Evol. Ecol. 11:641-672.

Bender, I.M.A. et al. 2017. Functionally specialised birds respond flexibly to seasonal changes in fruit availability. - J. Anim. Ecol. 86:800-811.

Böhning-Gaese, K. et al. 2006. Range size: disentangling current traits and phylogenetic and biogeographic factors. - Am. Nat. 167:555-567.

Burnham, K.P. and Anderson, D.R. 2002. Model selection and multimodel inference. - Springer, New York.

Chacoff, N.P. et al. 2012. Evaluating sampling completeness in a desert plant-pollinator network. - J. Anim. Ecol. 81:190-200.

Chase, J.M. and Leibold, M.A. 2003. Ecological niches. Linking classical and contemporary approaches. - The University of Chicago Press. Chicago and London.

Cohen, J.E. et al. 1993. Body sizes of animal predators and animal prey in food webs. - J. Anim. Ecol. 62:67-78.

Corlett, R.T. and Primack, R.B. 2011. Tropical rain forests: an ecological and biogeographical comparison. Second edition. - Blackwell Science Ltd, UK.

Coux, C. et al. 2016. Linking species functional roles to their network roles. - Ecol. Lett. 19: 762-770.

Dehling, D.M. et al. 2014. Functional relationships beyond species richness patterns: trait matching in plant-bird mutualisms across scales. - Global Ecol. Biogeogr. 23:1085-1093.

Dehling, D.M. et al. 2016. Morphology predicts species' functional roles and their degree of specialization in plant - frugivore interactions. - Proc. R. Soc. B. 283:20152444.

'This article is protected by copyright. All rights reserved'. 
Dray, S. and Legendre, P. 2008. Testing the species traits-environment relationships: the fourth-corner problem revisited. - Ecology 89:3400-3412.

Dunning, J.B. 2007. CRC Handbook of avian body masses. Second edition. - Taylor \& Francis, Boca Raton.

Elton, C. 1927. Animal ecology. - Sidgwick and Jackson, London.

Galetti, M. et al. 2013. Functional extinction of birds drives rapid evolutionary changes in seed size. - Science 340:1086-1090.

Garibaldi, L.A. et al. 2015. Trait matching of flower visitors and crops predicts fruit set better than trait diversity. - J. Appl. Ecol. 52:1436-1444.

Gravel, D. et al. 2013. Inferring food web structure from predator-prey body size relationships. - Methods Eco. Evol. 4:1083-1090.

Howe, H.F. and Smallwood, J. 1982. Ecology of seed dispersal. - Annu. Rev. Ecol. Syst. 13:201-228.

Howe, H.F. 2016. Making dispersal syndromes and networks useful in tropical conservation and restoration. Global Ecol. Conserv. 6:152-178.

Jansson, R. and Davies, J.T. 2008. Global variation in diversification rates of flowering plants: energy vs. climate change. - Ecol. Lett. 11:173-183.

Jordano, P. 1987. Patterns of mutualistic interactions in pollination and seed dispersal: connectance, dependence asymmetries, and coevolution. - Am. Nat. 129:657-677.

Jordano, P. 2016. Sampling networks of ecological interactions. - Funct. Ecol. 30:1883-1893.

Kessler-Rios, M.M., and Kattan, G.H. 2012. Fruits of Melastomataceae: Phenology in Andean forest and role as a food resource for birds. - J. Trop. Ecol. 28:11-21.

Kissling, W.D. et al. 2009. The global distribution of frugivory in birds. - Global Ecol. Biogeogr. 18:150-162.

Kissling, W.D. and Schleuning, M. 2015. Multispecies interactions across trophic levels at macroscales: retrospective and future directions. - Ecography 38:346-357.

Krebs, J.R. and Davies, N.B. 1993. An introduction to behavioural ecology. Fourth edition. - Blackwell, Oxford, UK.

Laliberté, E. (2011). Metacor: meta-analysis of correlation coefficients. R package version 1.0-2. http://CRAN.Rproject.org/package=metacor.

'This article is protected by copyright. All rights reserved'. 
Legendre, P. et al. 1997. Relating behaviour to habitat: solutions to the fourth-corner problem. - Ecology 78:547562.

Leisler, B. and Winkler, H. 1991. Ergebnisse und Konzepte ökomorphologischer Untersuchungen an Vögeln. - J. Ornithol. 132: 373-425.

Levey, D.J. 1987. Seed size and fruit-handling techniques of avian frugivores. - Am. Nat. 129:471-485.

Maglianesi, M.A. et al. 2015. Different foraging preferences of hummingbirds on artificial and natural flowers reveal mechanisms structuring plant - pollinator interactions. - J. Anim. Ecol. 84:655-664.

McKey, D.S. 1975. The ecology of coevolved seed dispersal systems. - In: Gilbert, E. and Raven, A.P. (ed.), Coevolution of animals and plants. University of Texas Press, Austin, pp 159-191.

Mello, M.A.R. et al. 2015. Keystone species in seed dispersal networks are mainly determined by dietary specialization. - Oikos 124:1031-1039.

Moermond, T.C. and Denslow, J.S. 1985. Neotropical avian frugivores: patterns of behavior, morphology, and nutrition, with consequences for fruit selection. - Ornithol. M. 36:865-897.

Morales-Castilla, I. et al. 2015. Inferring biotic interactions from proxies. - Trends Ecol. Evol. 30:347-356.

Müller, T. et al. 2014. Large frugivorous birds facilitate functional connectivity of fragmented landscapes. - J. Appl. Ecol. 51:684-692.

Muñoz, M.C. et al. 2017. Positive relationship between fruit removal by animals and seedling recruitment in a tropical forest. - Basic Appl. Ecol. 20:31-39.

Norberg, U.M. and Rayner, J.M.V. 1987. Ecological morphology and flight in bats (Mammalia; Chiroptera): wing adaptations, flight performance, foraging strategy and echolocation. - Philos. T. Roy. Soc. B. 316:335427.

Oksanen, J. et al. 2015. vegan: Community Ecology Package. R package version 2.2-1. http://CRAN.Rproject.org/package=vegan.

Olesen, J.M. et al. 2011a. Strong, long-term temporal dynamics of an ecological network. - PLoS ONE 6.

Olesen, J.M. et al. 2011b. Missing and forbidden links in mutualistic networks. - Proc. R. Soc. B. 278:725-732.

Petchey, O.L. et al. 2008. Size, foraging, and food web structure. - P. Natl. Acad. Sci. USA 105:4191-4196.

Rayner, J.M.V. 1988. Form and function in avian flight. - Curr Ornithol, 5:1-66.

'This article is protected by copyright. All rights reserved'. 
Saavedra, F. et al. 2014. Functional importance of avian seed dispersers changes in response to human-induced forest edges in tropical seed-dispersal networks. - Oecologia 176:837-848.

Schaefer, H.M. et al. 2002. Vertical stratification and caloric content of the standing fruit crop in a tropical lowland forest. - Biotropica 34:244-253.

Schleuning, M. et al. 2011. Specialization and interaction strength in a tropical plant-frugivore network differ among forest strata. - Ecology 92:26-36.

Schleuning, M. et al. 2015. Predicting ecosystem functions from biodiversity and mutualistic networks: an extension of trait-based concepts to plant-animal interactions. - Ecography 38:380-392.

Sebastián-González, E. 2017. Drivers of species' role in avian seed-dispersal mutualistic networks. - J. Anim. Ecol. 86:878:887.

Sebastián-González, E. et al. 2017. Species traits and interaction rules shape a species-rich seed-dispersal interaction network. - Ecol. Evol. 7:4496:4506.

Stang, M. et al. 2009. Size-specific interaction patterns and size matching in a plant-pollinator interaction web. Ann. Bot. London 103:1459-1469.

Swartz, S.M. et al. 2003. Ecomorphology of bats: comparative and experimental approaches relating structural design to ecology. - In: Kunz, T.H. and Fenton, M.B. (ed.), Bat ecology. University of Chicago Press, Chicago, Illinois, pp 257-300.

Ter Braak, C.J.F. et al. 2012. Improved testing of species traits-environment relationships in the fourth-corner problem. - Ecology 93:1525-1526.

Tucker, M.A. et al. 2016. Revisiting the cost of carnivory in mammals. - J. Evolution. Biol. 29:2181:2190.

Vidal, M.M. et al. 2013. Large vertebrates as the missing components of seed-dispersal networks. - Biol. Conserv. 163:42-48.

Viechtbauer, W. 2010. Conducting meta-analyses in R with the metafor package. - J. Stat. Softw. 36:1-48.

Waser, N.M. and Ollerton, J. 2006. Plant-pollinator interactions: from specialization to generalization. University of Chicago Press, Chicago, IL.

Wheelwright, N.T. 1985. Fruit-size, gape width, and the diets of fruit-eating birds. - Ecology 66:808-818.

Wheelwright, NT. 1988. Fruit-eating birds and bird-dispersed plants in the tropics and temperate zone. - Trends Ecol. Evol. 3:270-274.

'This article is protected by copyright. All rights reserved'. 
Woodward, G. and Warren, P. 2007. Body size and predatory interactions in freshwaters: scaling from individuals to communities. - In: Hildrew, A.G., Raffaelli, D. and Edmonds-Brown, R. (ed.), Body size: the structure and function of aquatic ecosystems. Cambridge University Press, Cambridge, UK, pages 98-117.

'This article is protected by copyright. All rights reserved'. 


\section{Figure Legends}

Fig. 1. Overview of the eight interaction networks sampled across the Andes. Networks represent interactions between fleshy-fruited plants (bottom boxes) and frugivorous birds (top boxes): Colombia 1 (2000 m a.s.l.), Colombia 2 (2500 m), Ecuador 1 (1000 m), Ecuador 2 (2000 m), Peru 1 (1500 m), Peru 2 (3000 m), Bolivia $(2500 \mathrm{~m})$ and Argentina $(1000 \mathrm{~m})$. Interactions between species are indicated by lines between boxes; box size and line width indicate the frequency of frugivore visits. For each network, the number of bird species, plant species and the total number of observed interaction events is given. The lines connect the networks to the location in South America where they were collected.

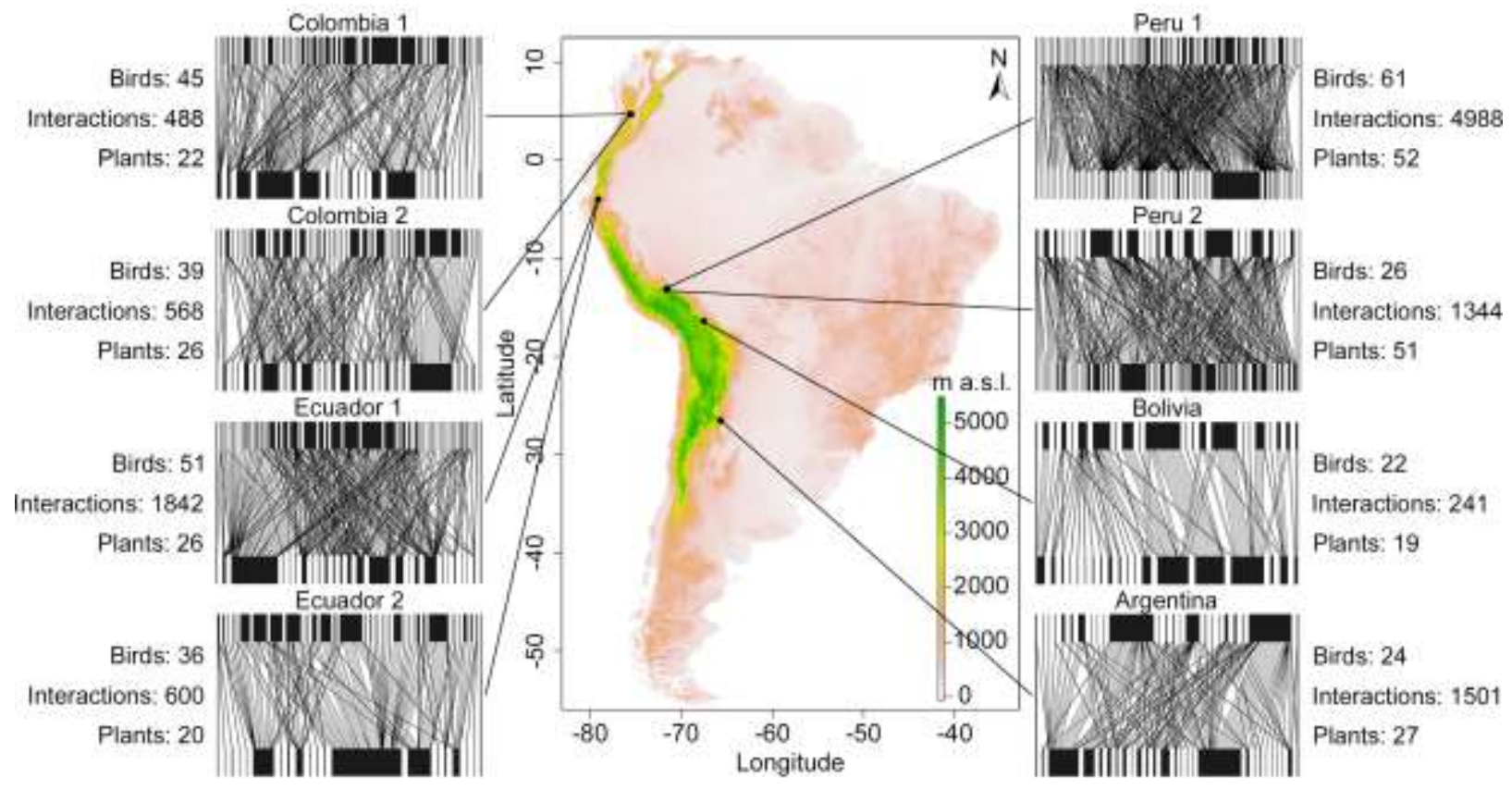

'This article is protected by copyright. All rights reserved'. 
Fig. 2. Matching of plant and frugivore traits across eight Andean networks. Results are derived from a metaanalysis of fourth-corner correlations between plant-frugivore trait pairs, weighted by sampling effort. Triangles indicate the mean of z-transformed Pearson's correlation coefficients $r$. Grey lines indicate the estimated variance of correlation coefficients. Asterisks indicate the level of significance for each trait pair $(* * *, P<0.001$; $*, P<0.05)$

Fruit diameter $\sim$ Bill width

Fruit length Bill length

Plant height $\sim$ Wing shape

Crop mass $\sim$ Body mass

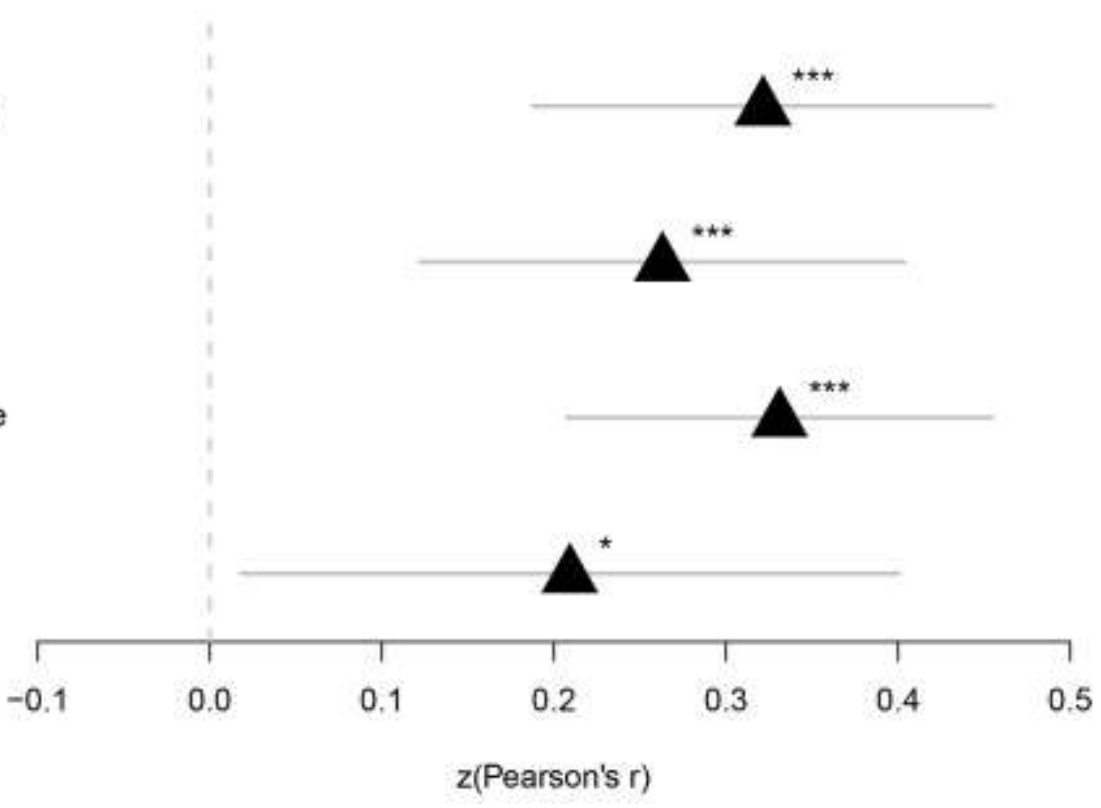

'This article is protected by copyright. All rights reserved'. 
Fig. 3. Relationships between morphological traits and species' functional specialization in (a) plants and (b) frugivorous birds and partial residual plots for the significant relationships in (c) plants and (d) birds, respectively. Results are obtained from mixed-effects models with functional specialization of plants or birds as response variable, and traits as predictor variables (plants: fruit diameter, fruit length, plant height and crop mass; birds: bill width, bill length, wing shape and body mass), including 'species identity' and 'network identity' as random effects. Functional specialization was measured by functional originality, i.e., the extent to which species interact with partners characterized by traits that only few other species interact with. Shown are results from model-averaged coefficients across a subset of best models $(\triangle \mathrm{AICc}<2)$. Grey estimates indicate variables that were not included in the set of best models. In (a) and (b), the relative variable importance is given and asterisks indicate the level of significance of the model-averaged estimates $(* * *, P<0.001 ; *, P<0.05)$. In (c) and (d), each dot represents a plant or a bird species in a specific network. Dot size and the degree of shading are proportional to the square-root number of observed interactions in the respective network.
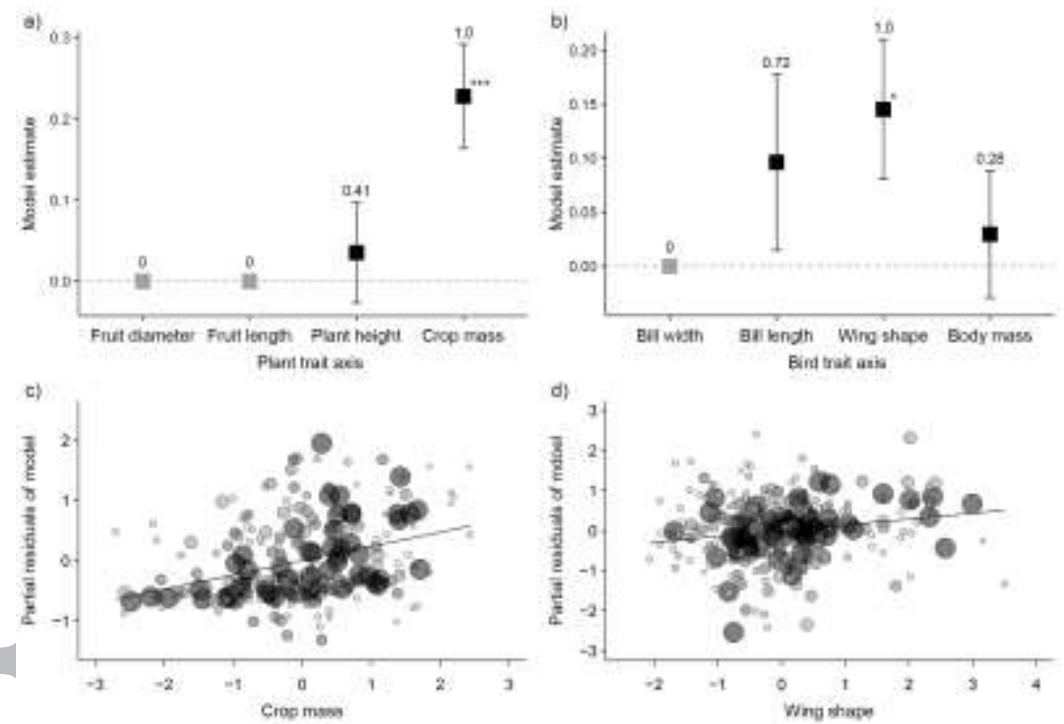

'This article is protected by copyright. All rights reserved'. 